\title{
CanMEDS and other outcomes
}

\author{
Geoff Norman
}

Received: 25 October 2011/Accepted: 25 October 2011/Published online: 19 November 2011

(C) Springer Science+Business Media B.V. 2011

As I indicated in a previous editorial (Norman 2007), the world of medical education is increasingly focused, for better or worse, on performance outcomes. One of the most influential taxonomies of outcomes is the CanMEDS roles, developed by the Royal College of Physicians and Surgeons of Canada beginning in 1993 (Frank et al. 1996). It is not alone, of course; we also have the ACGME competencies in the US, The Scottish Doctor and "Tomorrow's Doctor" in the UK, and several others I don't know about. But for reasons that I cannot begin to understand, the most widely adopted framework is the Canadian one, officially adopted by 16 countries.

To set the stage, the CanMEDS competencies, eight in number: Medical Expert/Clinical Decision-maker, Communicator, Collaborator, Manager, Health Advocate, Scholar, Professional are usually portrayed as a flower with Medical Expert at the centre surrounded by the other 7 roles. One wonders if the dissemination success of the competencies relate in part to the powerful visual appeal of the flower.

In this issue, we have two papers related to the CanMEDS roles, which, while using complementary methods, deliver a consistent message. The study by Whitehead et al. (2011) is quite unusual and a really interesting model for research. They recognized that the CanMEDS roles evolved from a large project involving all 5 (then) Ontario medical schools - the Educating Future Physicians of Ontario (EFPO) project, which in turn began in the late 1980's as a response to a bitter physician strike when government legislated against "extra-billing", i.e. private patients. The ground was fertile for a redefinition of what patients, in Ontario, really wanted from their physicians. Whitehead et al. combed through the archives of the EFPO project, box after box, in the University of Toronto, using Foucauldian discourse analysis. Their findings reveal a disconnect between the overt goal-information to better inform medical schools about the expectations of patients, and the covert message of a profession under siege:

The CanMEDS developers 'identified such forces as patient consumerism, government regulatory encroachment, financial imperatives, medical information in the internet, litigation, technology and the explosion in medical knowledge' (p. 643).

G. Norman $(\bowtie)$

Hamilton, ON, Canada

e-mail: norman@mcmaster.ca 
These 'forces' are portrayed as aspects of a hostile environment for which preparation and protection is needed. This list incorporates attacks on medical status in terms of the regulatory 'encroachment' and financial 'imperatives.' It also includes threats to medical authority and expertise in terms of increased patient access to information and a changed relationship with patients as "consumers" and litigators.

Whitehead et al. also dissect the "flower power" image of the CanMEDS logo, and suggest at least two more sinister ${ }^{1}$ interpretations of the image-as appendages to the central role of expert and as armour to protect the expertise. Whitehead's analysis is indeed provocative, and has led to a strong response by three other Canadian physicians, also in this issue (more on that in a moment).

The notion of "medical expert" as central and the remaining competencies as peripheral also arises, in a different guise, in a second paper in this issue by Jefferies et al. (2011). These authors examined 5 years of structured oral examination, and retrospectively identified questions related to each CanMEDS role. Although the category Medical Expert had good reliability across the exams (0.62), other patient-related roles had reliability between 0.19 and 0.46 . This difficulty in assessing the other roles echoes many comments I have heard from supervisors who have tried to grapple with teaching and assessing "collaborator", "advocate", and some of the other roles.

Finally, I draw readers' attention to a third paper on competency-based education, "A critical time for medical education: the perils of competence-based reform of the curriculum" by Malone and Supri (2010), which is available in Online First. This paper draws from four decades of research and experience in competency-based education to point to some relevant concerns about the approach.

Not surprisingly, Whitehead's thesis has engendered some criticism. Sherbino, Frank, Flynn and Snell (Frank is one of the authors of the original CanMEDS report) have written a commentary on their article that challenges some of the main assertions (Sherbino et al. 2011). In particular, they argue that "Medical Expert" is in the centre of the flower for the reason that it is "the Role that integrates the other Roles to provide a collective definition of physician competence", and suggest a change from "non-expert medical role" to "intrinsic role". And in turn, Whitehead et al. have written a brief rejoinder. All appear together in this issue.

The appearance of these papers together is a consequence of a unique opportunity that has emerged. AHSE enjoys the luxury of a very long publication queue, as the increases in the number of pages per issue (from 274 in 2003 to 778 in 2010) never seems to keep pace with the number of submissions. We have dealt with this by ensuring that papers are rapidly available in "Online First" soon after acceptance. Typically, a paper will be on Online First within a fortnight of approval of galleys by the author. However, there it languishes for about a year, for all to see, think about—and comment on. This long lag has created an opportunity for academic dialogue. We will be actively soliciting commentaries on any paper sitting in Online First. If approved, we will then ask the author to write a brief rejoinder. While we will be soliciting commentaries (editors-look out!) we also welcome any submission. These can be submitted in the usual manner through Editorial Manager, selecting the "Commentary" descriptor. The paper, commentary and rejoinder will appear together in a single issue, thanks to the dissociation between the speed of the paper and digital world.

\footnotetext{
1 Ironically it was the Canadian politician and Rhodes scholar, Tommy Douglas, the acknowledged father of our universal health care system and voted as Canada's top Canadian a few years ago, who cracked about the most clever trilingual pun I've ever read. He said, "The political left in Canada is more gauche than sinister".
} 
Fig. 1 Number of submissions to AHSE by year

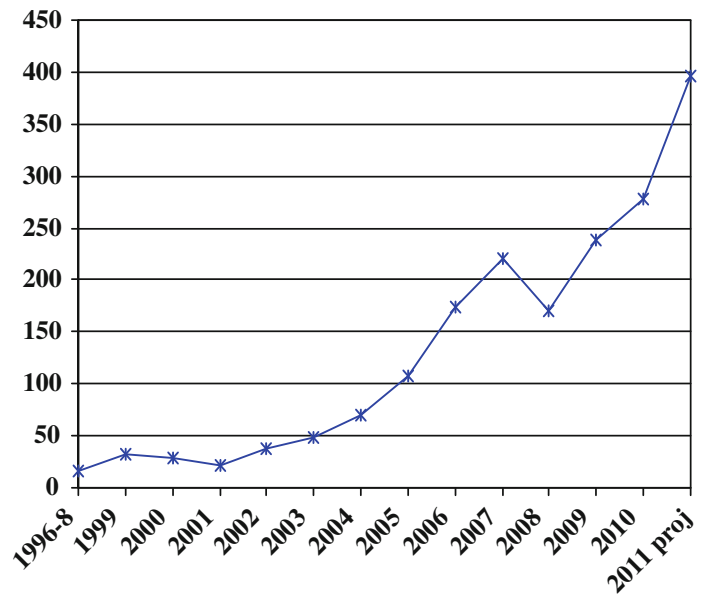

Let me now use this opportunity to describe some other changes at AHSE. As I indicated above, the number of submissions to the journal continues to increase almost exponentially. Figure 1 shows the number of submissions by year; this year alone, we are up $43 \%$ over 2010, to about 400 per year. About half of these submissions are turned down before peer review by the editors, usually because they do not fit within the explicit standards of the journal. The remainder are peer-reviewed. About $18-20 \%$ of submissions are accepted for publication.

The increase in submissions has serious implications at all stages of the process. To ensure that reviews are timely, we have done two things. First, Henk van Berkel, who has responsibility for the initial screen (so has the unenviable task of reading about 400 manuscripts a year!) has now been joined by his colleague at Maastricht, Jan van Dalen. Second, since the responsibility for shepherding the paper through the review process rests almost entirely on the associate editor, we have expanded the number of associate editors, from 10 three years ago to 26 today. We have provided a brief thumbnail of each of our new recruits below. Currently, this impressive panel represents 8 countries.

One important consequence of these changes is that, although the workload overall has gone up significantly, the time from submission to decision has actually gone down this year, from about 90 to 80 days for paper sent out for review (and less than a week for papers that are not reviewed). Of course we would like to shorten this further, and will continue to strive to do so.

A journal like AHSE is largely run by volunteers, who view it as a labour of love and a central part of their academic responsibility. So a huge thank you is due to our editors, Henk van Berkel and Jan van Dalen, our many associate editors, and of course, our many authors and readers, without whom the whole process would collapse.

\section{New editors at AHSE}

Co-editor

Jan van Dalen is coordinator of communication skills training and assessment at Maastricht University. He is very active in skills development and is responsible for the production of teaching materials and evaluation instruments, teaching of trainers, and research into the 
development of students' communication skills. He is Associate Editor of Education for Health, Associate Editor of Perspectives on Medical Education and Programme Director of the Master of Health Professions Education program at Maastricht University.

Associate editors

Kathy Boursicot is a Reader in Medical Education and Head of Assessment at St George's, University of London. She is the ASME Treasurer and the Chair of the Board of Management of ASME's journals, Medical Education and The Clinical Teacher. She is a member of the ASME Education Research Group. Her main research interests are in standard setting, the assessment of clinical competence and professionalism and she has published on standard setting, OSCEs and equity and diversity issues in medicine.

Rachel Ellaway is the Assistant Dean Curriculum and Planning, Associate Professor and Acting Director of Simulation at the Northern Ontario School of Medicine. Her research interests include educational informatics, simulation, e-health, technology in education, instructional design and the philosophy and sociology of medical education.

Richard Marz has a faculty appointment at the Medical University of Vienna where he serves as coordinator of the first year of studies. Since 2004 he has headed the Section of Science and International Relations of the Department of Medical Education. From 1995-2009 he served as the President of the Austrian Society for Didactics in Higher Education. He is a member of the editorial board of the "Zeitschrift fur Hochschulentwicklung" and since 1995 has co-organized and chaired the yearly "Grazer Conference on Medical Education."

Melchor Sanchez Mendiola is a pediatrician graduated from the Mexican Army and Air Force University, with a Master in Health Professions Education from the University of Illinois at Chicago. He is tenured Professor at the National Autonomous University of Mexico Faculty of Medicine, where he is Secretary of Medical Education and Director of the Master in Health Professions Education program. He is a member of the Society of Directors of Research in Medical Education and Editor of the new journal "Investigación en Educación Médica". His research interests are teaching residents to teach, medical education research and education in biomedical informatics.

David Prideaux is Emeritus Professor of Medical Education in the School of Medicine at Flinders University in South Australia. He is former Head of Health Professional Education and Deputy Dean. He is an educator by background with research interests in clinical education within longitudinal and distributed medical education programs.

Remy Rikers is a cognitive scientist who has conducted research on medical expertise development, instructional design, and problem-based learning. He is currently professor of Educational Psychology in the department of Psychology at the Erasmus University Rotterdam.

Lambert Schuwirth is a physician and educational researcher. He recently took an appointment at Flinders University, Australia. Prior to that, he was a professor in the Department of Medical Education at Maastricht University, Netherlands. His current research topic is innovative assessment, or more specifically research into assessment for learning (as opposed to assessment of learning).

David Swanson is currently the Vice President for Program Development and Special Projects in the Assessment Programs unit at the National Board of Medical Examiners (NBME). In that role, he works broadly on new NBME programs and services, international programs, and development of new assessment formats. 


\section{References}

Frank, J. R., Jabbour, M., Tugwell, P., et al. (1996). Skills for the new millennium: Report of the societal needs working group, CanMEDS 2000 Project. Annals Royal College of Physicians and Surgeons of Canada, 29, 206-216. Available at http://rcpsc.medical.org/canmeds/canmed_e.html.

Jefferies, A., Simmons, B., Ng, E., \& Skidmore, M. (2011). Assessment of multiple physician competencies in postgraduate training: Utility of the structured oral examination. Advances in Health Sciences Education. doi:10.1007/s10459-011-9275-6.

Malone, K., \& Supri, S. (2010). A critical time for medical education: the perils of competence-based reform of the curriculum. Advances in Health Sciences Education. doi:10.1007/s10459-010-9247-2.

Norman, G. R. (2007). Outcomes, objectives and the seductive appeal of simple solutions. Advances in Health Sciences Education, 11, 217-220.

Sherbino, J., Frank, J., Flynn, L., \& Snell, L. (2011). “Intrinsic Roles”' rather than "armour”: Renaming the "non-medical expert roles" of the CanMEDS framework to match their intent. Advances in Health Sciences Education, 16.

Whitehead, C. R., Austin, Z., \& Hodges, B. D. (2011). Intentions vs. unintended discursive consequences: Reflections upon Sherbino et al.'s commentary on "Flower Power". Advances in Health Sciences Education, 16. 